\title{
PENGARUH TINGKAT KESEHATAN TERHADAP PROFITABILITAS BPR PROVINSI KEPRI
}

\author{
Hesniati $^{1)}$, Novilia ${ }^{2)}$ \\ Program Studi Manajemen, Universitas Internasional Batam, Jl Gajah Mada, Batam \\ e-mail: hesniati.lec@uib.ac.id \\ Program Studi Manajemen, Universitas Internasional Batam, Jl Gajah Mada, Batam \\ e-mail: nchovlyines@yahoo.com
}

\begin{abstract}
This research is examining CAMEL ratio effects profitability of rural banks. The population in this study is rural banks in Riau Island Province listed in the Indonesia Financial Service Authority in 2012 until 2016. Samples were taken by using purposive sampling method. Total samples used in this research are 23 companies with total observation 115 data. The data obtained will be tested with regression panel method. The result showed that variables of BOPO, Cash Ratio, and NPL are significant negative with the profitability. KAP and LDR are insignificant with profitability of rural banks.
\end{abstract}

Keywords: profitability, rural banks, CAMEL ratio

\begin{abstract}
Abstrak
Penelitian ini bertujuan untuk menguji rasio CAMEL berpengaruh kepada profitabilitas Bank Perkreditan Rakyat (BPR). Populasi pada penelitian ini merupakan BPR di Kepulauan Riau yang terdaftar di Otoritas Jasa Keuangan (OJK) pada kurun tahun 2012 hingga 2016. Sampel penelitian menggunakan metode purposive sampling. Total sampel dalam penelitian adalah 23 perusahaan dengan total 115 data observasi. Data yang diperoleh akan diuji dengan metode panel regresi. Hasil penelitian mengungkapkan variabel BOPO, Cash Ratio, dan NPL berpengaruh negatif terhadap profitabilitas. KAP dan LDR tidak berpengaruh dengan profitabilitas BPR.
\end{abstract}

Kata kunci: profitabilitas, BPR, rasio CAMEL

\section{PENDAHULUAN}

Bank Perkreditan Rakyat merupakan bank yang memiliki keterbatasan tidak diperboleh adanya fungsi jasa lalu lintas pembayaran sehingga kegiatan usaha BPR hanya sebagai penerimaan dana dan penyaluran pinjaman kepada masyarakat. Meski fungsinya tidak sekomplit bank umum, namun kinerja pertumbuhan kredit dan aset dari BPR mengalami peningkatan setiap tahun. Gambar 1 menunjukkan bahwa pertumbuhan kredit dari tahun 2012 sampai dengan 2016 telah mengalami peningkatan sebesar 71 persen dan untuk pertumbuhan aset juga mengalami peningkatan sebesar 70 persen. Grafik ini menunjukkan kinerja perusahaan BPR yang semakin meningkat. 


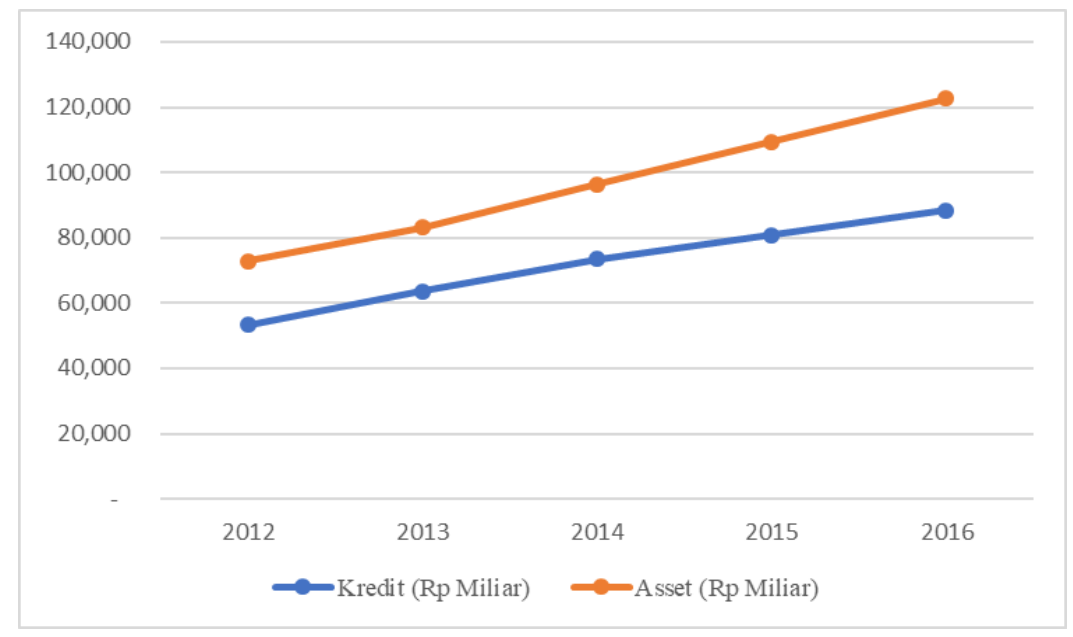

Gambar 1 Pertumbuhan Kredit dan Aset BPR tahun 2012 sampai dengan 2016, sumber: Otoritas Jasa Keuangan, 2017.

Namun, disatu sisi hasil dari laporan tahunan Lembaga Penjamin Simpanan (LPS) menyebutkan sejak berdirinya LPS dari tahun 2005 hingga 2017 sudah ada 84 perusahaan BPR yang dilikuidasikan dari tahun ke tahun. Penyebab utama dari kegagalan BPR adalah fraud (Lembaga Penjamin Simpanan, 2017). Padahal fraud dapat menurunkan kinerja perbankan dan mengakibatkan perbankan mengalami kesulitan keuangan (Gitau \& Samson, 2016) sehingga sangat penting untuk mengukur tingkat kesehatan bank agar tidak terjadi kerugian dari pihak perbankan dan kepada nasabah.
Analisis
CAMEL
(Capital

Adequacy, Asset Quality, Management, Equity, dan Liquidity) adalah analisis yang berupa rasio untuk tingkat kesehatan bank. Munir dan Bustamam (2017) pada penelitiannya di Malaysia dan Indonesia mengungkapkan untuk meningkatkan kinerja perusahaan dan mengurangi risiko fraud perbankan dapat dilakukan dengan analisis CAMEL. Hasil penelitian tersebut juga didukung oleh Zedan dan Daas (2017) bahwa analisis CAMEL berpengaruh terhadap profitabilitas perbankan di Pakistan serta penelitian Iheanyi dan Sotonye (2017) dan Ebrahimi,
Bahraminasab, dan Seyedi (2017) juga menunjukkan CAMEL dapat memprediksi kinerja perusahaan perbankan. Dari paparan diatas, maka pada penelitian ini mengajukan hipotesis berupa:

$\mathrm{H}_{1}$ : BOPO berpengaruh signifikan negatif terhadap profitabilitas perusahaan BPR.

$\mathrm{H}_{2}$ : Cash Ratio berpengaruh signifikan negatif terhadap profitabilitas perusahaan BPR.

$\mathrm{H}_{3}$ : KAP berpengaruh signifikan negatif terhadap profitabilitas perusahaan BPR.

$\mathrm{H}_{4}$ : LDR berpengaruh signifikan negatif terhadap profitabilitas perusahaan BPR.

$\mathrm{H}_{5}$ : NPL berpengaruh signifikan negatif terhadap profitabilitas BPR.

\section{METODE PENELITIAN}

Penelitian ini bersifat kuantitatif dan pengujiannya melalui pengukuran variabel yang menggunakan angka dan statistik (Creswell, 2014). Objek penelitian pada studi ini adalah BPR yang terdaftar di Provinsi Kepulauan Riau. Penentuan sampel menggunakan sampel yang dipilih dengan kriteria yang ditentukan untuk mencapai tujuan penelitian (purposive sampling). Kriteria pengambilan sampel adalah: 
1. Terdaftar di OJK.

2. Memiliki laporan keuangan yang 3. Melakukan penutupan buku laporan lengkap.

Variabel operasional pada penelitian akan dijelaskan dibawah ini:

\section{Return on Assets (ROA)}

ROA merupakan tingkat pengembalian asset dari sebuah perusahaan (Munir \& Bustamam, 2017).

$\mathrm{ROA}=\frac{\text { Laba Bersih sebelum Bunga dan Pajak }}{\text { Total Aset }}$

2. Biaya Operasional per Pendapatan Operasional (BOPO)

BOPO merupakan rasio untuk mengetahui perbandingan biaya operasional dan pendapatan operasional bank tersebut. BOPO digunakan untuk mengukur kemampuan perusahaan menghasilkan keuntungan (Hanantijo, Armayasari, \& Respati, 2018).

$\mathrm{BOPO}=\frac{\text { Biaya Operasional }}{\text { Pendapatan Operasional }} \times 100 \%$

\section{Cash Ratio}

Cash Ratio untuk menentukan kemampuan untuk memenuhi kewajibannya melalui aset likuid yang dimiliki. Rasio ini digunakan untuk mengukur kemampuan perusahaan untuk menyediakan dana dalam membayar kewajibannya (Rahmat, 2018).

Metode analisis panel data diterapkan pada penelitian ini karena metode ini dapat menyelidiki hubungan antara variabel independen dengan variabel dependen pada data longitudinal. Tahapan analisis data dimulai dari statistik deskriptif, uji outlier, pemilihan model terbaik dengan Uji Chow dan Uji keuangan pada bulan Desember.

Cash Ratio $=\frac{\text { Aset Likuid }}{\text { Kewajiban segera }+ \text { Tab }+ \text { Deposito }} \times 100 \%$

4. Kualitas Aktiva Produktif

KAP merupakan pengukuran penerimaan kembali dana yang tertanam di aktiva yang produktif pada $\times$ sebuah perbankan (Rahmat, 2018). $\mathrm{KAP}=\frac{\text { Total kredit yang tidak lancar }(K L, D, M)}{\text { Total aktiva produktif }} \times 100 \%$

\section{Loan to Deposit Ratio (LDR)}

LDR merupakan perbandingan komposisi seluruh pinjaman yang disalurkan terhadap dana pihak ketiga yang diterima. LDR digunakan untuk mengukur likuiditas perbankan dalam menghadapi masalah kredit (Hanantijo et al., 2018).

$\mathrm{LDR}=\frac{\text { Total Kredit yang Diberikan }}{\text { Tabungan }+ \text { Deposito }} \times 100 \%$

\section{Non-Performing Loan (NPL)}

NPL adalah pengukuran tentang pinjaman bank yang mengalami kesukaran dalam penagihan yang diakibatkan internal ataupun eksternal faktor yang tidak dapat diatur oleh pengutang. Rasio NPL digunakan untuk menentukan kualitas aset perbankan (Hanantijo et al., 2018).

$$
\mathrm{NPL}=\frac{\text { Total Kredit yang Tidak Lancar }(K L, D, M)}{\text { Total Kredit }} \times 100 \%
$$

Hausman, Uji F, Uji t, dan pengukuran Goodness of Fit Model.

\section{HASIL DAN PEMBAHASAN}

Berikut ini merupakan tampilan dari daftar sampel BPR yang digunakan pada penelitian pada Tabel 1 dan pengujian statistik deskriptif pada Tabel 2. 
Tabel 1

Daftar Sampel BPR

Keterangan

BPR Konvensional yang terdaftar di OJK

BPR yang dijadikan sampel

Total data 2012-2016

Total data outlier

Total data bebas outlier

Sumber: Data sekunder diolah (2019).

Tabel 2

Hasil Uji Statistik Deskriptif

\begin{tabular}{lc}
\hline Effect Test & Prob. \\
\hline Cross-section F & 0,0004 \\
Cross-section Chi- & 0,0000 \\
square & \\
\hline
\end{tabular}

Tabel 3

Uji Chow

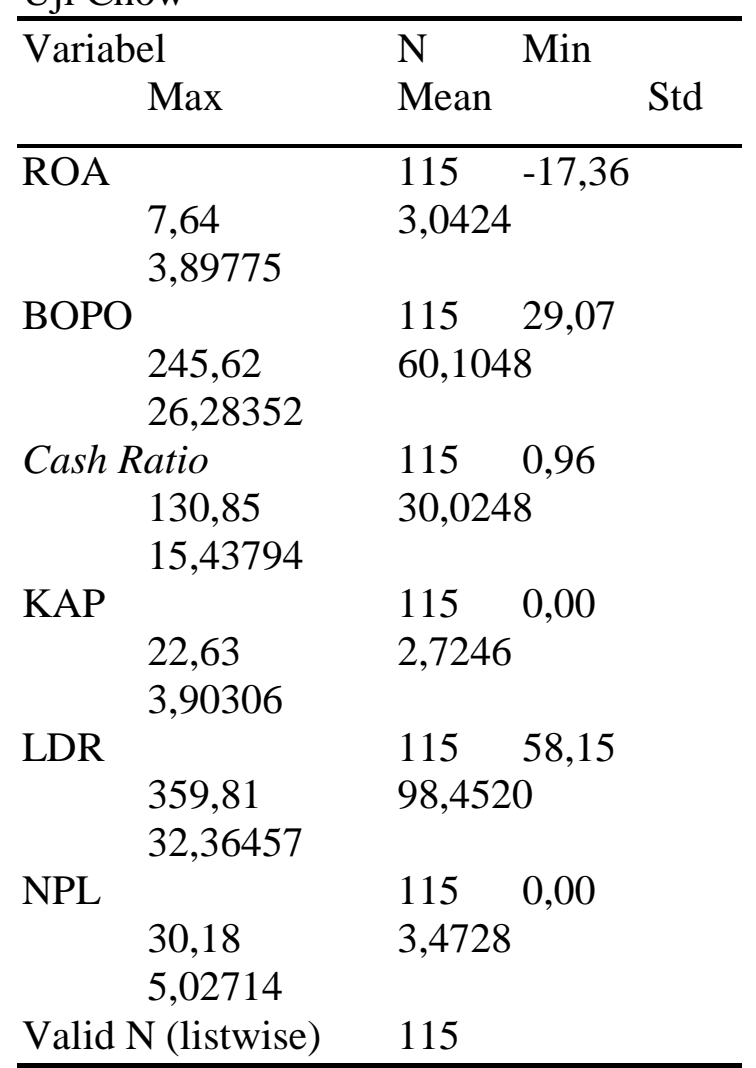

Sumber: Data sekunder yang diolah (2019).
Uji Chow dilakukan dengan melihat nilai probabilitas pada Cross-Section Chisquare bilJunilah signifikansi kurang dari 0,05 mak42akerns dilakakan uji Hausman

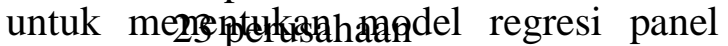
yang terbaik5ydar dapat dilihat dari Tabel 3. Hasil daridati) probabilitas pada crosssection rqododataadalah sebesar 0,0200 kemudian akan dilakukan Uj1 Hausman. Pada pengujian Hausman menunjukkan fixed effect model yang diterima.

\section{Uji Hausman}

\begin{tabular}{lc}
\hline Test Summary & Prob. \\
\hline Cross-section random & 0,0200 \\
\hline Sumber:
\end{tabular}

Sumber: Data sekunder diolah (2019).

Berdasarkan pengujian nilai probabilitas uji $\mathrm{F}$ dihasilkan nilai sebesar 0,000 menunjukkan variabel independen yaitu BOPO, Cash Ratio, KAP, LDR, dan NPL keseluruhan berpengaruh terhadap profitabilitas.

Tabel 4

Hasil uji $F$

Variabel

Dependen $\quad$ Prob. $\quad$ Kesimpulan

ROA $\quad 0,0000 \quad$ Signifikan

Sumber: Data sekunder diolah (2019).

Tabel 5

Hasil uji $t$

\begin{tabular}{cllll}
\hline Variabel & Coefficient & t-Statistic & Prob. & Signifikan \\
\hline C & 9,633174 & 19,11501 & 0,0000 & Signifikan positif \\
BOPO & $-0,050852$ & $-6,748867$ & 0,0000 & Signifikan negatif \\
CR & $-0,043730$ & $-4,026151$ & 0,0001 & Signifikan negatif \\
KAP & 0,184627 & 1,009525 & 0,3158 & Tidak terdapat signifikan \\
LDR & $-0,008488$ & $-1,270818$ & 0,2075 & Tidak terdapat signifikan \\
NPL & $-0,471068$ & $-3,335467$ & 0,0013 & Signifikan negatif \\
\hline
\end{tabular}

Sumber: Data sekunder diolah (2019). 
Hasil uji $\mathrm{F}$ menunjukkan bahwa BOPO berpengaruh negatif terhadap ROA sehingga konsisten dengan Hanantijo et al. (2018), Chou dan Buchdadi (2016), dan Raharjo, Setiaji, dan Syamsudin (2014). Jika BOPO meningkat, maka semakin besar biaya operasional yang terjadi dan dapat menurunkan pendapatan perbankan. Cash ratio berpengaruh negatif terhadap profitabilitas BPR dan konsisten dengan hasil penelitian Yahaya dan Bala (2015). Hal ini disebabkan cash ratio yang tinggi mengindikasikan ada kas yang tidak bergerak pada perbankan karena dana yang diterima seperti tabungan dan deposito, pihak perbankan tidak mampu menyalurkan kembali dalam bentuk kredit. Hasil uji KAP tidak konsisten dengan penelitian Eman (2013) bahwa KAP berpengaruh terhadap profitabilitas BPR. LDR tidak signifikan terhadap profitabilitas BPR dan konsisten dengan hasil penelitian Buchory (2015) dan bertentangan dengan Hanantijo et al. (2018). NPL berpengaruh signifikan negatif terhadap profitabilitas BPR dan hasilnya serupa dengan Raharjo et al. (2014) dan Eman (2013). Hasil ini membuktikan bahwa BPR harus menyediakan cadangan penyisihan untuk menghapus kredit apabila nasabah tidak dapat membayarkan kewajiban yang seharusnya diterima kembali dan mengakibatkan NPL menjadi naik dan profit perusahaan turun.

Hasil dari uji goodness of fit model pada Tabel 6 menunjukkan model penelitian ini memiliki persentase sebesar $88,05 \%$ dijelaskan oleh kelima variabel independen penelitian dan sisanya dijelaskan oleh variabel yang lain.
Tabel 6

Hasil uji Goodness of Fit Model

\begin{tabular}{lll}
\hline Variabel Dependen & $\mathrm{R}^{2}$ & Adjusted $\mathrm{R}^{2}$ \\
\hline ROA & 0,910685 & 0,880542 \\
\hline Sumber: Data sekunder diolah $(2019)$. &
\end{tabular}

Sumber: Data sekunder diolah (2019).

\section{SIMPULAN}

Penelitian ini bertujuan untuk menguji CAMEL berpengaruh terhadap profitabilitas Bank Perkreditan Rakyat (BPR). Hasil penelitian mengungkapkan variabel BOPO, Cash Ratio, dan NPL berpengaruh negatif terhadap profitabilitas. KAP dan LDR tidak berpengaruh dengan profitabilitas BPR. Peneliti merekomendasikan kepada manajerial BPR untuk memperhatikan segi BOPO, Cash Ratio, dan NPL dalam meningkatkan profitabilitas perusahaan.

\section{DAFTAR PUSTAKA}

Buchory, H. A. (2015). Banking intermediation, operational efficiency and credit risk in the banking profitability. International Journal of Business, Economics and Law, 7(2), 57-63.

Chou, T.-K., \& Buchdadi, A. D. (2016). Bank Performance and Its Underlying Factors: A Study of Rural Banks in Indonesia. Accounting and Finance Research, 5(3), 55-63. https://doi.org/10.5430/afr.v5n3p55

Creswell, J. W. (2014). Research design: Qualitative, Quantitative, and Mixed Methods Approaches (4th editio). Unitred States of America: SAGE Publications Ltd.

Ebrahimi, S. K., Bahraminasab, A., \& Seyedi, F. S. (2017). The Impact of CAMEL Indexes on Profit Management in Banks Listed on Tehran Stock Exchange, 7(2), 421- 
429.

Eman, G. M. I. (2013). Pengaruh Kualitas Aktiva Produktif Dan Kredit Bermasalah Terhadap Profitabilitas PT. Bank Tabungan Pensiunan Nasional, Tbk Gabriela Mike Ineke Eman. Jurnal Ilmu Administrasi, 9(3), 1-8.

Gitau, E. W., \& Samson, N. G. (2016). Effect of financial fraud on the performance of commercial banks: a case study of tier 1 banks in Nakuru Town, Kenya. International Journal of Economics, Commerce and Management, 4(12), 142-157.

Hanantijo, D., Armayasari, T. U., \& Respati, H. (2018). CAMEL Method: Bank Health Levels for Financial Performance of Banking in Indonesia Stock Exchange Period 2006 to 2015. Research Journal of Finance and Accounting, 9(7), 146152.

Iheanyi, I. H., \& Sotonye, I. (2017). Assessing the Performance of Nigeria', s Bank through Camel Model. Journal of Accounting and Finance Management, 3(1), 14-22.

Lembaga Penjamin Simpanan. (2017). Transformasi mennjadi yang terdepan. Retrieved from https://www.lps.go.id/documents/101 57/118031/20180710_AR+LPS+201 7.pdf/178c652a-ef26-4847-8753$762 \mathrm{~b} 3 \mathrm{fb} 12 \mathrm{f} 81$

Munir, M. binti B., \& Bustamam, U. S. A. (2017). Camel Ratio on Profitability Banking Performance (Malaysia Versus Indonesia). International Journal of Management, Innovation
\& Entrepreneurial Research, 3(1), 30 . https://doi.org/10.18510/ijmier.2017. 314

Otoritas Jasa Keuangan. (2017). Laporan Kinerja Otoritas Jasa Keuangan 2012-2017.

Raharjo, D. P. A., Setiaji, B., \& Syamsudin. (2014). Pengaruh rasio CAR, NPL, LDR, BOPOm dan NIM terhadap kinerja bank umum di Indonesia. Jurnal Manajemen Dayasaing, 15(2), 7-12. https://doi.org/https://doi.org/10.2391 7/dayasaing.v16i2.2047

Rahmat. (2018). Camel Analysis on Bank Perkreditan Rakyat (Empirical Studies PT. BPR Intan Jabar). International Journal of Scientific and Research Publications, 8(2), 144-153.

Republik Indonesia. (1998). UndangUndang No. 10 Tahun 1998 tentang Perbankan. Jakarta.

Yahaya, A., \& Bala, H. (2015). Working Capital Management and Financial Performance of Deposit Money Banks in Nigeria. Research Journal of Finance and Accounting, 6(16), 57-72.

https://doi.org/https://doi.org/10.9734 /BJEMT/2015/15132

Zedan, K. A., \& Daas, G. (2017). International Journal of Economics and Financial Issues Palestinian Banks Analysis Using CAMEL Model. International Journal of Economics and Financial Issues, 7(1), 351-357. Retrieved from http:\%0Awww.econjournals.com 